\title{
Epigallocatechin-3-gallate Protects against Hydrogen Peroxide-Induced Inhibition of Osteogenic Differentiation of Human Bone Marrow-Derived Mesenchymal Stem Cells
}

\author{
Dawei Wang, ${ }^{1}$ Yonghui Wang, ${ }^{1}$ Shihong Xu, ${ }^{1}$ Fu Wang, ${ }^{1}$ Bomin Wang, ${ }^{1}$ Ke Han, \\ Daqing Sun, ${ }^{2}$ and Lianxin $\mathrm{Li}^{1}$ \\ ${ }^{1}$ Department of Orthopedics, Shandong Provincial Hospital Affiliated to Shandong University, Jinan 250021, China \\ ${ }^{2}$ Department of Vascular Surgery, Second Hospital of Shandong University, Jinan 250000, China \\ Correspondence should be addressed to Daqing Sun; bigqsun@sina.com and Lianxin Li; lxli23@sina.com
}

Received 23 October 2015; Revised 22 December 2015; Accepted 24 December 2015

Academic Editor: Gary E. Lyons

Copyright ( 2016 Dawei Wang et al. This is an open access article distributed under the Creative Commons Attribution License, which permits unrestricted use, distribution, and reproduction in any medium, provided the original work is properly cited.

\begin{abstract}
Oxidative stress induces bone loss and osteoporosis, and epigallocatechin-3-gallate (EGCG) may be used to combat these diseases due to its antioxidative property. Herein, oxidative stress in human bone marrow-derived mesenchymal stem cells (BM-MSCs) was induced by $\mathrm{H}_{2} \mathrm{O}_{2}$, resulting in an adverse effect on their osteogenic differentiation. However, this $\mathrm{H}_{2} \mathrm{O}_{2}$-induced adverse effect was nullified when the cells were treated with EGCG. In addition, treatment of BM-MSCs with EGCG alone also resulted in the enhancement of osteogenic differentiation of BM-MSCs. After EGCG treatment, expressions of $\beta$-catenin and cyclin D1 were upregulated, suggesting that the Wnt pathway was involved in the effects of EGCG on the osteogenic differentiation of BMMSCs. This was also confirmed by the fact that the Wnt pathway inhibitor, Dickkopf-1 (DKK-1), can nullify the EGCG-induced enhancement effect on BM-MSC's osteogenic differentiation. Hence, our results suggested that EGCG can reduce the effects of oxidative stress on Wnt pathway in osteogenic cells, which supported a potentially promising therapy of bone disorders induced by oxidative stress. Considering its positive effects on BM-MSCs, EGCG may also be beneficial for stem cell-based bone repair.
\end{abstract}

\section{Introduction}

Several types of polyphenols, including green tea polyphenols, grape polyphenols, and blueberry polyphenols, have been reported to be capable of promoting bone formation, preventing bone loss, and influencing osteogenic differentiation [1-4]. Epigallocatechin-3-gallate (EGCG) is the most abundant catechin polyphenol extracted from green tea, constituting $9-13 \%$ of the total dry weight [5]. After oral administration, EGCG is predominantly absorbed in the small intestine followed by transportation to other organs. Thus, due to its antioxidant and free radical scavenger properties, EGCG has been proposed to have protective effects for organ impairments induced by ischemia, toxins, stress, and hypertension $[6,7]$.

Oxidative stress may be associated with the pathophysiology of many organs. In bone tissues, generation of reactive oxygen species (ROS) can influence the homeostasis, since
ROS contributes to bone remodeling by promoting bone resorption [8]. Recent studies suggested that some bone pathogenesis, such as osteoporosis, diabetes-induced bone complications, bone tumor development, and joint inflammatory diseases, may be associated with oxidative stress [9].

EGCG is beneficial for bone regeneration, possibly due to its ability to suppress bone resorption and inhibit functions of osteoclasts. EGCG has been shown to induce apoptotic cell death in cultured mouse osteoclasts and inhibit the formation of osteoclasts in a coculture system of mouse bone marrow cells and calvarial primary osteoblasts [10]. In addition, it has also been reported that EGCG can increase the differentiation of human osteoblast-like cells by reducing the expression of Runt-related transcription factor 2 (Runx2) in the late growth stage [11].

Bone marrow-derived mesenchymal stem cells (BMMSCs) are an attractive cell source for bone defect repair, 
due to their relatively simple isolation and expansion procedures, as well as their pluripotent differentiation ability into mesenchymal tissues [12]. BM-MSCs are commonly used ex vivo in combination with three-dimensional (3D) porous biomaterial carriers to form a bone construct, which can be implanted to the defect sites to facilitate repair process by subsequent osteogenesis of the construct [13-15]. In addition, BM-MSCs can also be used in the absence of biomaterial carriers. Direct infusion of BM-MSCs systemically or through intrabone has been used to treat various degenerative bone disorders, such as osteogenesis imperfecta and osteoporosis [16-18].

This study aimed to investigate the potential protective roles of EGCG against the adverse effects of oxidative stress on osteogenic differentiation of BM-MSCs, as well as the possible underlying mechanisms. Oxidative stress in BMMSCs was induced by $\mathrm{H}_{2} \mathrm{O}_{2}$, and the combined treatment of BM-MSCs with EGCG and $\mathrm{H}_{2} \mathrm{O}_{2}$ was used to investigate the potential effects of EGCG against oxidative stress. The possible involvement of Wnt pathway in the antioxidative effects of EGCG was also investigated.

\section{Materials and Methods}

2.1. Isolation and Culture of Human BM-MSC. Human BMMSCs were isolated from marrow extracts harvested from a healthy donor without specific metabolic or inherited diseases. The marrow extracts were obtained with informed consent via routine iliac bone graft procedure for reconstruction of bone defects resulting from traumatic tibial fracture. The bone marrow tissue was washed out with growth medium containing Alpha-Modified Eagle's Medium ( $\alpha$-MEM; Gibco, USA) supplemented with $10 \%$ fetal bovine serum (FBS; Hyclone, USA), $100 \mathrm{U} / \mathrm{L}$ penicillin, and $100 \mathrm{U} / \mathrm{L}$ streptomycin (Solarbio, China). After centrifugation, the cells were suspended in the growth medium and maintained under a humidified atmosphere with $5 \% \mathrm{CO}_{2}$ at $37^{\circ} \mathrm{C}$. After $24 \mathrm{~h}$ of culture, the medium was refreshed to remove nonadherent cells. BM-MSCs were used when the culture reached $80-90 \%$ confluence. This study was approved by the ethics committee of Shandong Provincial Hospital affiliated to Shandong University.

2.2. Flow Cytometry. The expression of surface markers CD29, CD44, and CD105 (as positive markers) and CD34 (as a negative marker) on the isolated BM-MSCs was tested using the following antibodies (all purchased from Abcam, UK): FITC-conjugated mouse anti-human CD29, FITC-conjugated mouse monoclonal anti-human CD44, FITC-conjugated mouse monoclonal anti-human CD105, and FITC-conjugated mouse monoclonal anti-human CD34. Flow cytometric analysis was conducted on a FACSCalibur platform (BD Biosciences, NJ). Unstained cells were used for gate setting, and at least 15,000 events were collected for analysis of each sample.

2.3. Treatment of BM-MSCs with $\mathrm{H}_{2} \mathrm{O}_{2}$, EGCG, and Dickkopf-1 (DKK-1). To induce osteogenic differentiation of
BM-MSCs, the cells were cultured in differentiation medium containing $\alpha$-MEM medium supplemented with $10 \%$ FBS, $50 \mu \mathrm{g} / \mathrm{mL}$ L-ascorbic acid (Sigma, USA), $10 \mathrm{mM} \beta$ glycerophosphate (Sigma), and $100 \mathrm{nM}$ dexamethasone (Sigma). Various amounts of $\mathrm{H}_{2} \mathrm{O}_{2}$ and/or EGCG (Sigma) were added to the differentiation medium for investigation of their effects on M-MSCs. Cells cultured in medium without $\mathrm{H}_{2} \mathrm{O}_{2}$ and EGCG were used as control. To investigate whether Wnt pathway is involved in osteogenic differentiation of BM-MSCs, $0.2 \mu \mathrm{g} / \mathrm{mL}$ Wnt inhibitor, Dickkopf-1 (DKK1; Peprotech, USA), was added to the culture medium containing $0.2 \mathrm{mM} \mathrm{H}_{2} \mathrm{O}_{2}$ and $5 \mu \mathrm{M}$ EGCG.

2.4. Cell Viability Assay. Cell viability was measured using Cell Counting Assay Kit 8 (CCK-8; Sigma, USA) according to the manufacturer's protocol. BM-MSCs were seeded onto 96-well plates $\left(5 \times 10^{3}\right.$ cells/well $)$ and maintained in growth medium overnight. After removal of the medium, fresh medium containing different concentrations of $\mathrm{H}_{2} \mathrm{O}_{2}$ and/or EGCG was added. After incubation for $24 \mathrm{~h}, 10 \mu \mathrm{L}$ of CCK8 solution was added to each well to incubate for $1 \mathrm{~h}$, and the absorbance at $450 \mathrm{~nm}$ was measured with a microplate reader (Molecular Devices, USA).

2.5. Glutathione (GSH) Level Measurement. To measure GSH level, the cells were lysed with $200 \mu \mathrm{L}$ of RIPA Lysis Buffer (Beyotime Institute of Biotechnology, China) containing $1 \mathrm{mM}$ phenylmethanesulfonyl fluoride (PMSF). $20 \mu \mathrm{L}$ of cell lysate was treated with $5 \%$ trichloroacetic acid and then mixed with $660 \mu \mathrm{L}$ of $67 \mathrm{mM}$ sodium and potassium phos-

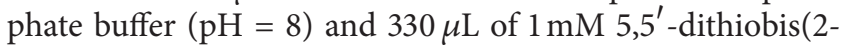
nitrobenzoate) (DTNB). The samples were incubated at room temperature in the dark for $45 \mathrm{~min}$ and the absorbance at $412 \mathrm{~nm}$ was measured. GSH concentration was calculated based on a calibration curve obtained using commercial standards.

2.6. Superoxide Dismutase (SOD) Activity and Malondialdehyde (MDA) Level Measurement. SOD activity was measured using a Superoxide Dismutase (ransod) Diluent Assay kit (Randox Laboratories Ltd.) according to the manufacturer's instruction. MDA level was measured with detection kits (Jiancheng Biotech, Nanjing, China) according to the manufacturer's instructions. Briefly, $100 \mathrm{~mL}$ thiobarbituric acid (TBA) solution containing $15 \mathrm{~mL}$ of $100 \%$ trichloroacetic acid, $0.375 \mathrm{~g}$ of TBA, $25 \mathrm{~mL}$ of $1 \mathrm{~N}$ hydrochloric acid $(\mathrm{HCl})$, and $40 \mathrm{mg}$ of butylated hydroxytoluene (BHT)/ethanol was freshly prepared. $1 \mathrm{~mL}$ of TBA solution and $15 \mu \mathrm{L}$ of $50 \mathrm{mM}$ BHT were added to $0.5 \mathrm{~mL}$ of samples. The mixture was heated at $95^{\circ} \mathrm{C}$ for $45 \mathrm{~min}$ and then cooled in ice-cold water to measure the absorbance at $532 \mathrm{~nm}$ on a spectrophotometer.

2.7. Alkaline Phosphatase (ALP) Activity Assay. To examine the effect of EGCG on the ALP activity of BM-MSCs, $3 \times$ $10^{4}$ cells were seeded on 24-well microplate and cultured in the osteogenic differentiation medium (as mentioned above) containing various concentrations of EGCG. After 8 days of culture, cells were washed with phosphate-buffered 
saline (PBS) and stained with an ALP staining kit (Nanjing Jiancheng Bioengineering Research Institute, China) following the manufacturer's instructions. The staining was then observed under a microscope (IX71, Olympus, Japan). To quantify the ALP activity, the cells were lysed with $200 \mu \mathrm{L}$ of RIPA Lysis Buffer (Beyotime Institute of Biotechnology, China) containing $1 \mathrm{mM}$ phenylmethanesulfonyl fluoride (PMSF), followed by measuring the ALP activity (units $/ \mathrm{mL}$ ) with an ALP reagent kit (Nanjing Jiancheng Bioengineering Research Institute) as per the manufacturer's instructions.

2.8. Calcium Accumulation Assay. Calcium accumulation assay was conducted using Alizarin Red staining. After 16 days of culture, cells were washed with distilled water and fixed with ice-cold $70 \%(\mathrm{v} / \mathrm{v})$ ethanol for $1 \mathrm{~h}$. After rising twice with deionized water, the cells were stained with Alizarin Red S (ARS; Sigma, USA) solution ( $40 \mathrm{mM}$ in TRIS buffer, $\mathrm{pH} 4.2$ ) for 10 min at room temperature, and the excess dye was gently washed away with water. The stained calcification deposits (red) were examined under a microscope (Olympus, Japan). The Alizarin Red-sulfate staining density was determined by melting the stained sample using $10 \%(\mathrm{w} / \mathrm{v})$ cetylpyridinium chloride dissolved in $10 \mathrm{mM}$ sodium phosphate ( $\mathrm{pH} 7.0)$ and measuring at $562 \mathrm{~nm}$.

\subsection{Quantitative Reverse Transcription Polymerase Chain} Reaction ( $q R T-P C R)$. qRT-PCR was performed for the detection of the osteogenic gene expression of cells cultured in 6-well plates. Total RNA was harvested with a Reverse Transcription System (Promega, USA) according to the manufacturer's instructions, and $1 \mathrm{mg}$ of the extracted total RNA was used for cDNA synthesis. qRT-PCR was conducted on an ABI 7300 Sequence Detection System (Applied Biosystems, USA) using TaqMan Universal PCR Master Mix (Applied Biosystems, USA). The primers used are Runx2 (forward: $5^{\prime}$-TGTCATGGCGGGTAACGATG-3', reverse: $5^{\prime}$-CCCTAAATCACTGAGGCGGT- $3^{\prime}$ ), osterix (OSX, forward: $5^{\prime}$-CCTCTGCGGGACTCAACAAC- $3^{\prime}$, reverse: $5^{\prime}$-AGCCCATTAGTGCTTGTAAAGG- $3^{\prime}$ ), $\beta$-catenin (forward: $5^{\prime}$-AAAGCGGCTGTTAGTCACTGG- $3^{\prime}$, reverse: $5^{\prime}$ CGAGTCATTGCATACTGTCCAT- $3^{\prime}$ ), cyclin D1 (forward: $5^{\prime}$-GCTGCGAAGTGGAAACCATC- $3^{\prime}$, reverse: $5^{\prime}$-CCTCCTTCTGCACACATTTGAA-3'), and glyceraldehyde-3phosphate dehydrogenase (GAPDH, forward: $5^{\prime}$-CTATAAATTGAGCCCGCAGC- $3^{\prime}$, reverse: $5^{\prime}$-GACCAAATCCGTTGACTCCG- ${ }^{\prime}$ ). Gene expression level was calculated using $2^{-\triangle \Delta C t}$ method with GAPDH as the reference gene.

2.10. Western Blotting. Homogenization of BM-MSCs was conducted with a Polytron homogenizer for $10 \mathrm{~s}$ in cold Pro-PREP protein extraction solution (Intron, Seongnam, Korea) containing $1 \mathrm{mM}$ pepstatin A, $1 \mathrm{mM}$ PMSF, $0.1 \mathrm{mM}$ aprotinin, $1 \mathrm{mM}$ leupeptin, and $1 \mathrm{mM}$ EDTA. Cell lysates were kept at $-20^{\circ} \mathrm{C}$ for $30 \mathrm{~min}$. After centrifugation for $10 \mathrm{~min}$ at $10,000 \times \mathrm{g}$, the concentration of proteins in the supernatant was determined with an enhanced BCA protein assay kit (Beyotime Institute of Biotechnology). After boiling in $5 \mathrm{x}$ sample buffer (50 mM Tris, 2\% (w/v) SDS, 5\% (v/v) glycerol, and $10 \%(\mathrm{v} / \mathrm{v}) 2$-mercaptoethanol, $\mathrm{pH} 6.8), 50 \mathrm{mg}$ of the total proteins was separated by molecular mass on $12 \%(\mathrm{w} / \mathrm{v})$ sodium dodecyl sulfate-polyacrylamide gel electrophoresis (SDS-PAGE) gels, with $5 \%(\mathrm{w} / \mathrm{v})$ polyacrylamide stacking gels. The expression levels of the following proteins were determined: $\beta$-catenin $(88 \mathrm{kDa})$, cyclin $\mathrm{D} 1(35 \mathrm{kDa})$, and GAPDH $(37 \mathrm{kDa})$.

Separated proteins were transferred onto polyvinylidene fluoride (PVDF) membranes (Bio-Rad), which were then blocked with $5 \%(\mathrm{w} / \mathrm{v})$ skim milk in Tris-buffered saline containing $0.1 \%(\mathrm{v} / \mathrm{v})$ Tween 20 , and incubated with commercial primary antibodies $(1: 1,000$ dilution; all purchased from Abcam, UK): mouse monoclonal anti-human GAPDH, rabbit monoclonal anti-human $\beta$-catenin, and rabbit monoclonal anti-human cyclin D1. Blots were then incubated with secondary horseradish peroxidase-conjugated anti-mouse or anti-rabbit antibodies (1:5,000 dilutions; Abcam) followed by development with an enhanced chemiluminescence detection kit (Millipore, USA). Signal intensity was quantified by an EZ-Capture II chemiluminescence imaging system with a charge-cooled camera (Atto Corp., Japan). Relative protein levels were expressed as the ratio of the intensity of each protein to the intensity of GAPDH.

2.11. Statistical Analysis. For each condition and time point, a minimum of three independent experiments were carried out. One- or two-way analysis of variance (ANOVA) with Tukey post hoc test was used to evaluate the data and the results are presented as mean \pm SEM. Statistical significance was accepted at $p<0.05$.

\section{Results}

3.1. Effects of $\mathrm{H}_{2} \mathrm{O}_{2}$ and EGCG on BM-MSC's Viability. The isolated human BM-MSCs were identified by flow cytometry analysis for expressions of common surface markers of MSCs. As shown in Figure 1(a), the majority of the cells expressed CD29, CD44, and CD105, whereas few cells expressed CD34. This indicated that the isolated cells were indeed BM-MSCs. CCK- 8 assay results demonstrated that the viability of BMMSCs was reduced with increasing concentrations of $\mathrm{H}_{2} \mathrm{O}_{2}$ in the cell culture medium. The viability of BM-MSCs started to decrease when treated with $0.2 \mathrm{mM} \mathrm{H}_{2} \mathrm{O}_{2}$, and the $\mathrm{IC}_{50}$ value was approximately $0.5 \mathrm{mM}$ (Figure $1(\mathrm{~b})$ ). The concentrationdependent effects of EGCG on the viability of BM-MSCs were also investigated. Incubation with 5 and $10 \mu \mathrm{M}$ EGCG for $24 \mathrm{~h}$ significantly enhanced cell viability, whereas further elevation in EGCG concentration did not affect the viability of the cells (Figure 1(c)). Therefore, $5 \mu \mathrm{M}$ EGCG was selected as the optimal concentration for subsequent experiments. BM-MSCs were then treated with the combination of $0.2 \mathrm{mM}$ $\mathrm{H}_{2} \mathrm{O}_{2}$ and $5 \mu \mathrm{M}$ EGCG, and the results showed that EGCG almost completely nullified the $\mathrm{H}_{2} \mathrm{O}_{2}$-induced reduction on cell viability over 7 days (Figure 1(d)).

3.2. Effects of $\mathrm{H}_{2} \mathrm{O}_{2}$ and EGCG on the Oxidative Stress Status of BM-MSCs. As shown in Figure 2(a), GSH level was reduced when BM-MSCs were treated with $0.2 \mathrm{mM} \mathrm{H}_{2} \mathrm{O}_{2}$, 

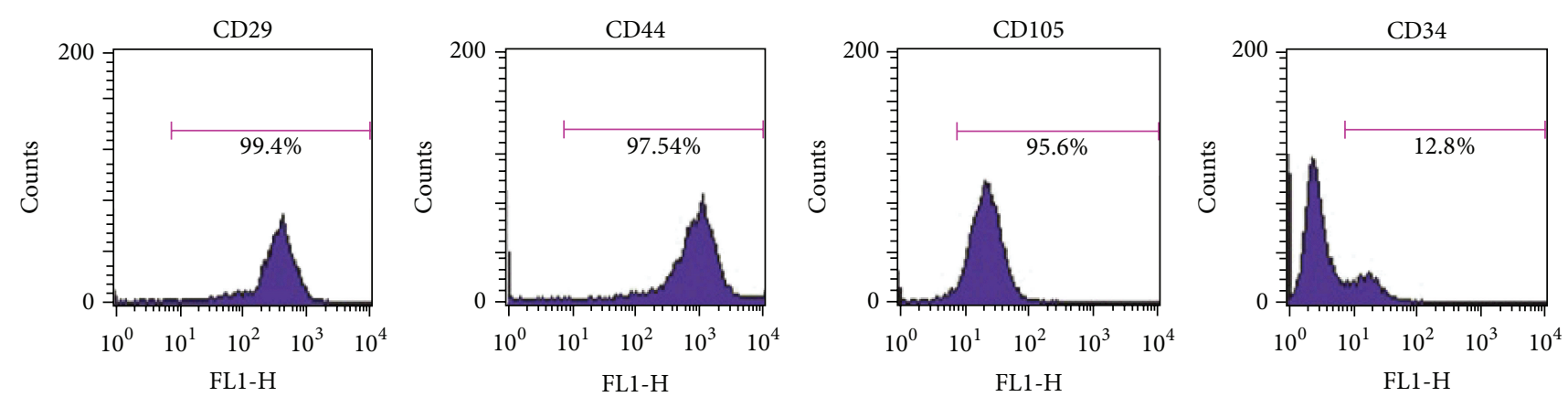

(a)

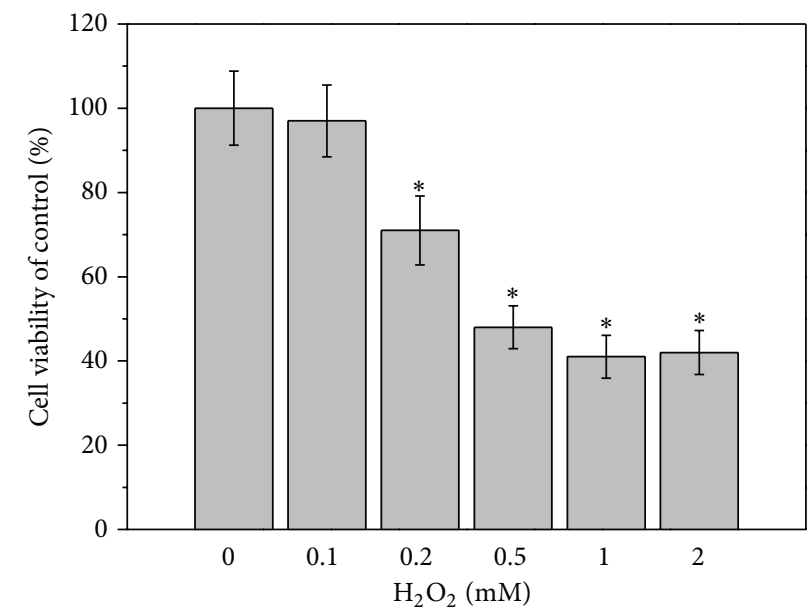

(b)

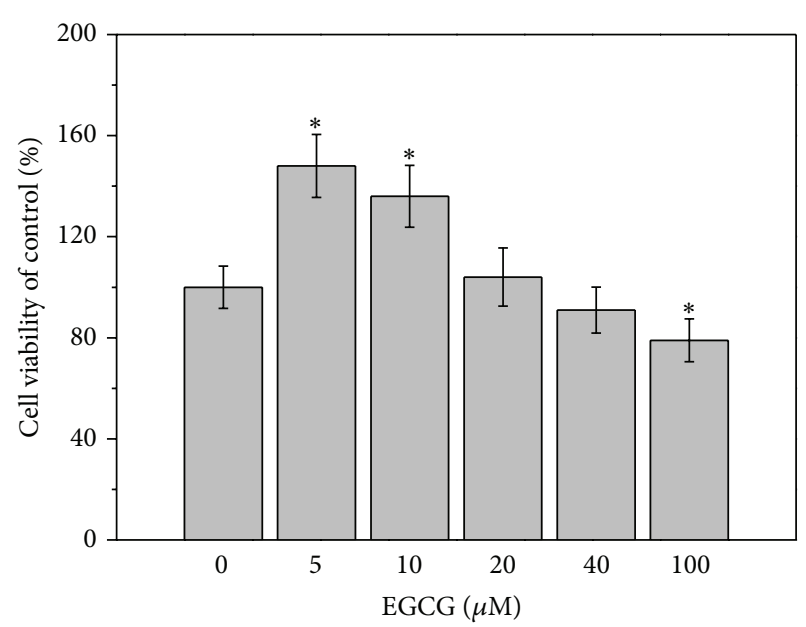

(c)

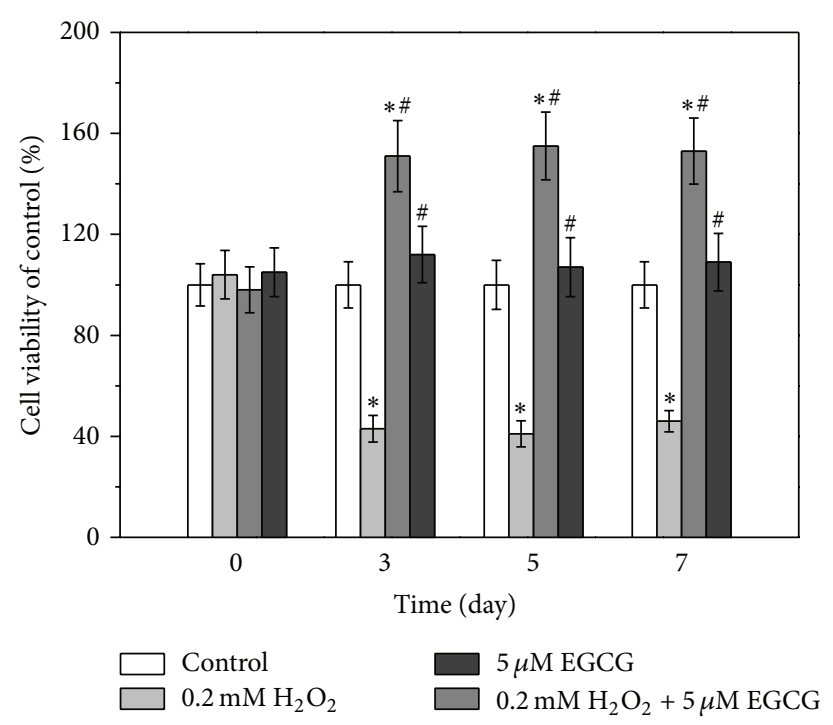

(d)

FIGURE 1: Effects of $\mathrm{H}_{2} \mathrm{O}_{2}$ and EGCG on cell viability of human BM-MSCs. (a) Characterization of human BM-MSCs by flow cytometry. The majority of the cells are CD29+, CD44+, CD105+, and CD34-, which are typical characteristic phenotypes of BM-MSCs. Effects of different concentrations of $\mathrm{H}_{2} \mathrm{O}_{2}$ exposure ( 0.1 to $2 \mathrm{mM}$ ) (b) or EGCG exposure (5 to $100 \mu \mathrm{M}$ ) (c) for 24 h on cell viability of BM-MSCs, measured by MTT assay. (d) Cotreatment of $0.2 \mathrm{mM} \mathrm{H}_{2} \mathrm{O}_{2}$ and $5 \mu \mathrm{M}$ EGCG for indicated time on cell viability of BM-MSCs. Data were presented as mean \pm SEM. ${ }^{*} p<0.05$ versus control and ${ }^{\#} p<0.01$ versus $0.2 \mathrm{mM} \mathrm{H}_{2} \mathrm{O}_{2}$ treatment alone. 


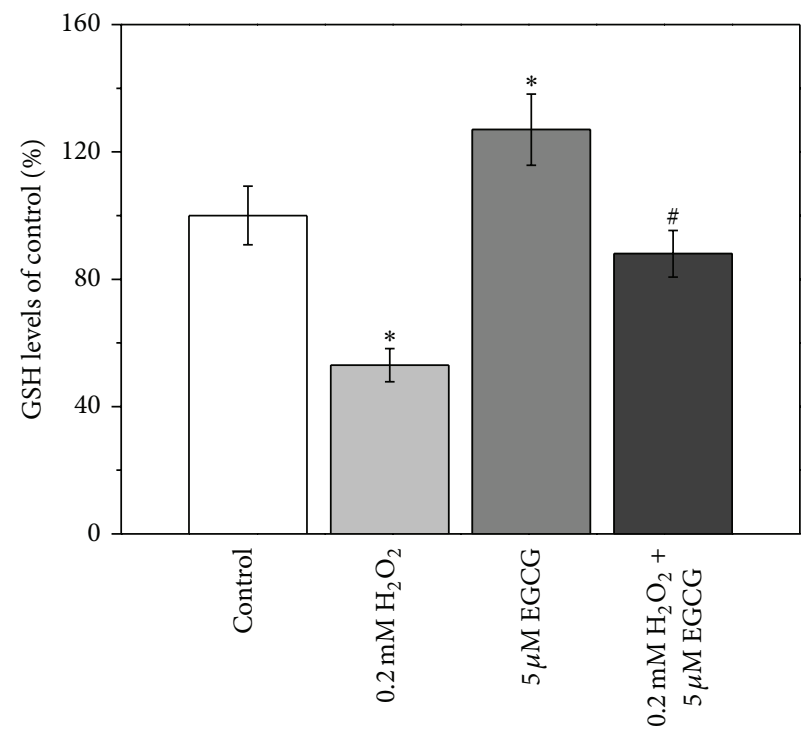

(a)

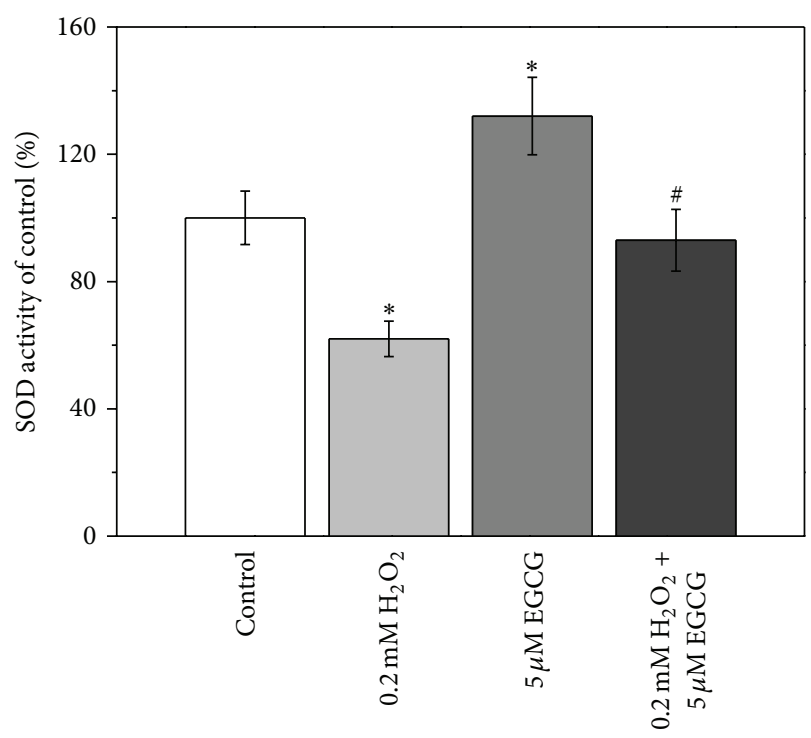

(b)

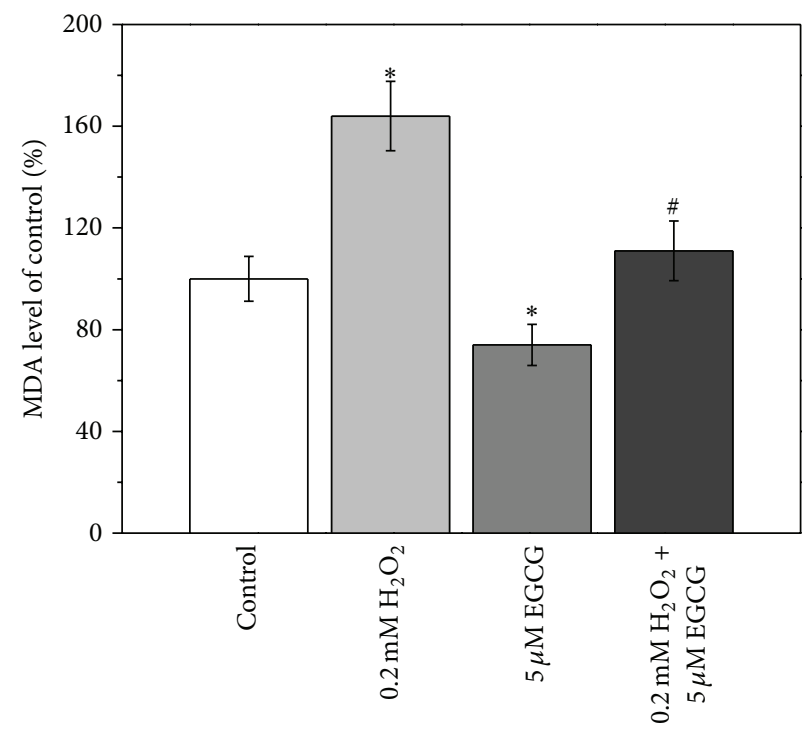

(c)

FIGURE 2: $5 \mu \mathrm{M}$ EGCG attenuates $0.2 \mathrm{mM} \mathrm{H}_{2} \mathrm{O}_{2}$-induced oxidative stress in human BM-MSCs. GSH levels (a), SOD activity (b), and MDA levels (c) were shown in the cells when cultured for 7 days. Data were presented as mean \pm SEM. ${ }^{*} p<0.05$ versus control and ${ }^{\#} p<0.05$ versus $0.2 \mathrm{mM} \mathrm{H}_{2} \mathrm{O}_{2}$ treatment alone.

whereas treatment with $5 \mu \mathrm{M}$ EGCG significantly elevated the GSH level. When the cells were cotreated with $\mathrm{H}_{2} \mathrm{O}_{2}$ and EGCG, the GSH level was restored to the same level as the control group. Similar trends in the changes of SOD levels were also observed, when BM-MSCs were treated with $\mathrm{H}_{2} \mathrm{O}_{2}$, EGCG alone, and combined treatment with $\mathrm{H}_{2} \mathrm{O}_{2}$ and EGCG, respectively (Figure 2(b)). However, the situation was different for MDA level. Treatment of BM-MSCs with $0.2 \mathrm{mM}$ $\mathrm{H}_{2} \mathrm{O}_{2}$ resulted in an increase in the MDA level, whereas when the cells were treated with $5 \mu \mathrm{M}$ EGCG, the MDA level was lower than that of control (Figure 3(c)). The combinational treatment with EGCG and $\mathrm{H}_{2} \mathrm{O}_{2}$ restored MDA level similar to that of control.
3.3. Effects of $\mathrm{H}_{2} \mathrm{O}_{2}$ and EGCG on the Osteogenic Differentiation of BM-MSCs. As compared with control, when BMMSCs were treated with $0.2 \mathrm{mM} \mathrm{H}_{2} \mathrm{O}_{2}$, the extent of ALP and ARS staining was significantly reduced, whereas treatment with EGCG resulted in enhanced staining (Figure 3(a)). When BM-MSCs were cotreated with $\mathrm{H}_{2} \mathrm{O}_{2}$ and EGCG, the extent of ALP and ARS staining became significantly higher than that of control (Figure 3(a)). Quantitative analysis of ALP activity and calcium deposition showed similar results (Figures 3(b) and 3(c)). As compared with control, treatment with $0.2 \mathrm{mM} \mathrm{H}_{2} \mathrm{O}_{2}$ resulted in approximately $60 \%$ decrease in the ALP activity and calcium deposition content. When the cells were cotreated with $\mathrm{H}_{2} \mathrm{O}_{2}$ and EGCG, the ALP activity 


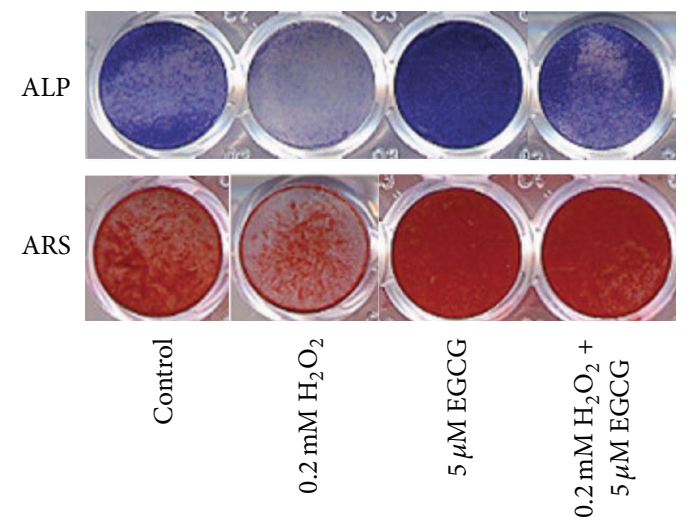

(a)

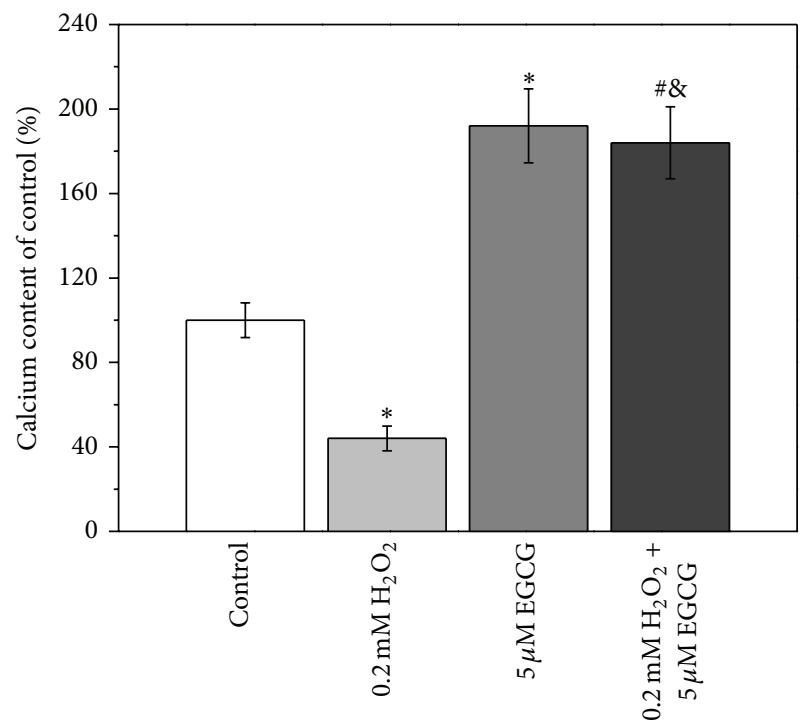

(c)

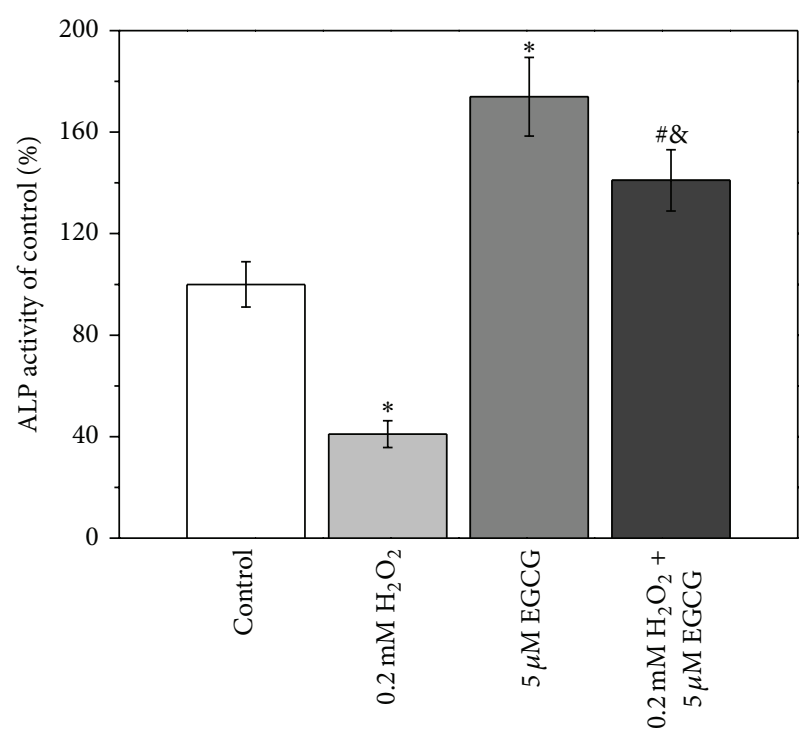

(b)

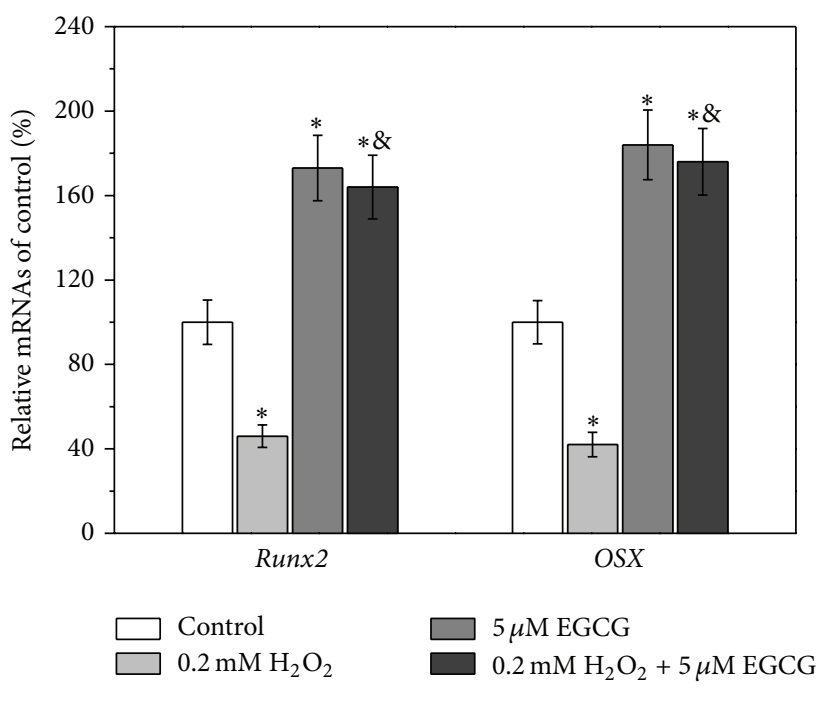

(d)

FIGURE 3: $5 \mu \mathrm{M}$ EGCG protects against $0.2 \mathrm{mM} \mathrm{H} \mathrm{H}_{2} \mathrm{O}_{2}$-induced inhibition of osteogenic differentiation of human BM-MSCs. (a) Representative ALP and ARS staining images in the four experimental groups. ALP activity (b) and calcium contents (c) of the cultures of the experimental groups normalized to control. (d) Relative mRNAs expression of Runx2 and OSX in the experimental groups, quantified by RT-PCR. Data were presented as mean \pm SEM. ${ }^{*} p<0.01$ and ${ }^{\#} p<0.05$ versus control, and ${ }^{\&} p<0.01$ versus $0.2 \mathrm{mM} \mathrm{H}_{2} \mathrm{O}_{2}$ treatment alone.

increased by approximately 30\%, and calcium deposition content increased by approximately $70 \%$. The expression levels of osteogenic markers of BM-MSCs after the different treatment were also investigated, and similar results were obtained (Figure 3(d)).

3.4. Involvement of Wnt Pathway in the Protective Effects of EGCG from Oxidative Stress. As shown in Figure 4(a), Western blot results indicated that treatment of BM-MSCs with $0.2 \mathrm{mM} \mathrm{H}_{2} \mathrm{O}_{2}$ reduced the expression levels of $\beta$ catenin and cyclin D1, while treatment with $5 \mu \mathrm{M}$ EGCG can nullify this downregulated effect induced by $\mathrm{H}_{2} \mathrm{O}_{2}$ by restoring the expression levels of these two regulators of Wnt pathway. Similar results were obtained by qRT-PCR analysis (Figure 4(b)). As described above, when BM-MSCs were cotreated with $\mathrm{H}_{2} \mathrm{O}_{2}$ and EGCG, the osteogenic differentiation of BM-MSCs was enhanced as compared to control. However, the enhancement effects were significantly reduced when DKK1 was added. The ALP activity, calcium deposition, and the expression levels of Runx2 and OSX in the DKK-1treated group were similar or even lower than those of control (Figures 4(c)-4(e)). 


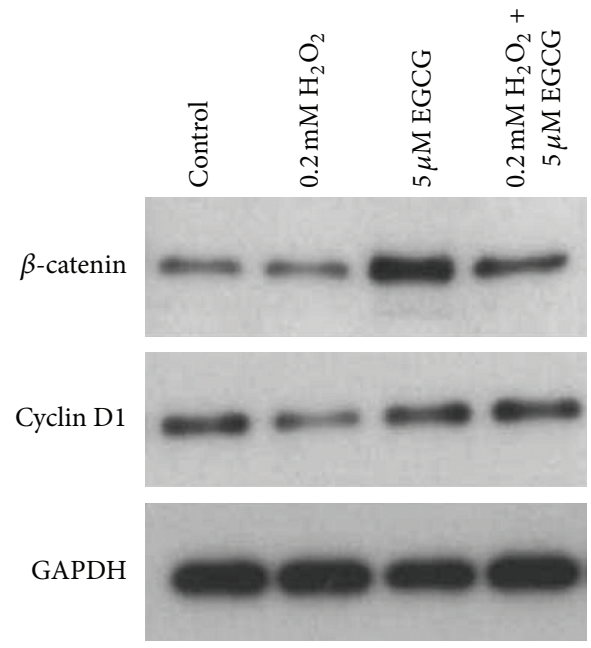

(a)

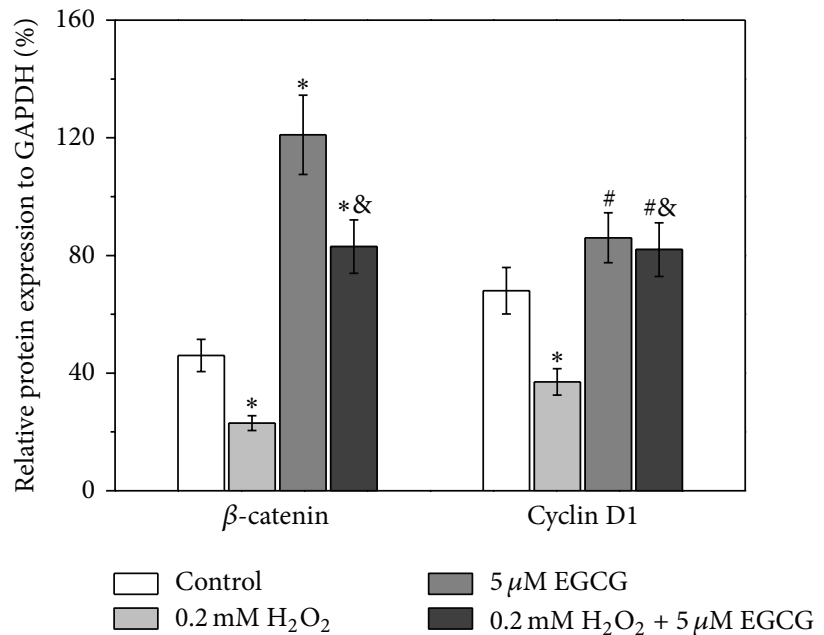

(b)

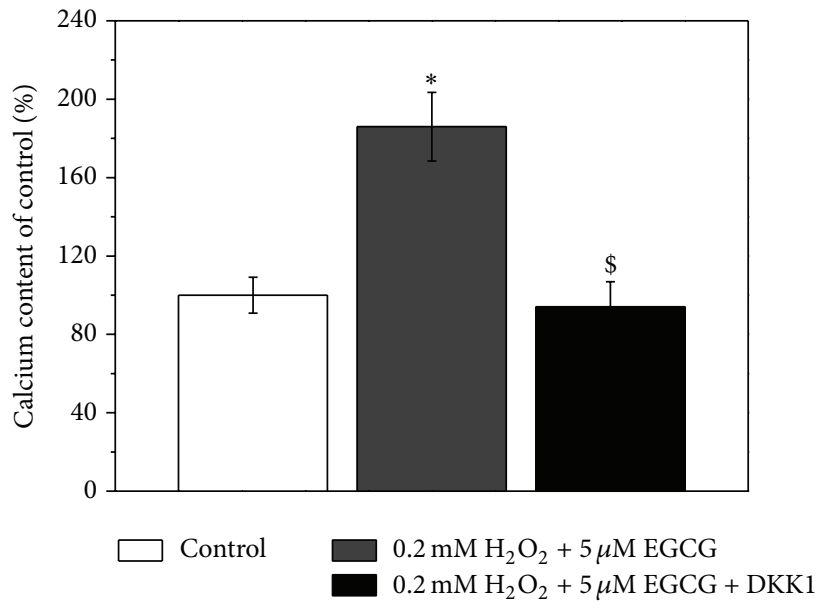

(d)

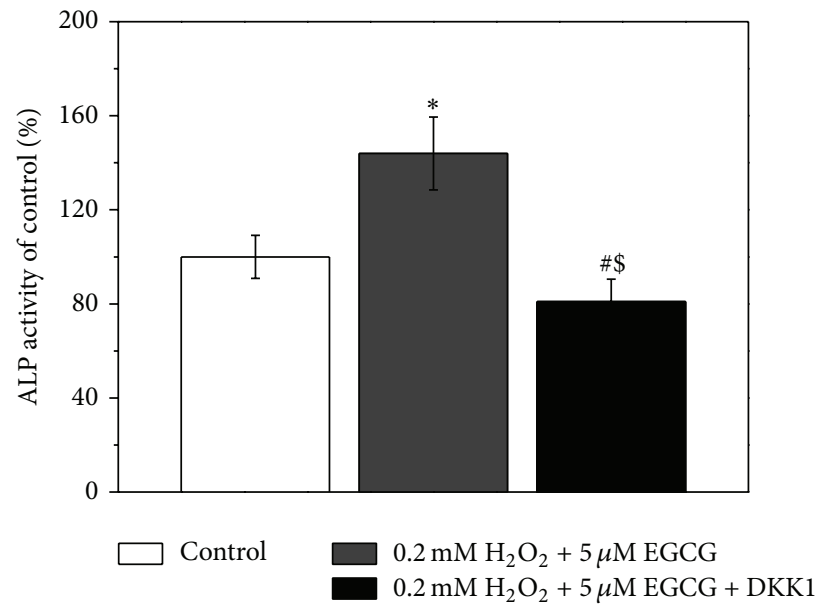

(c)

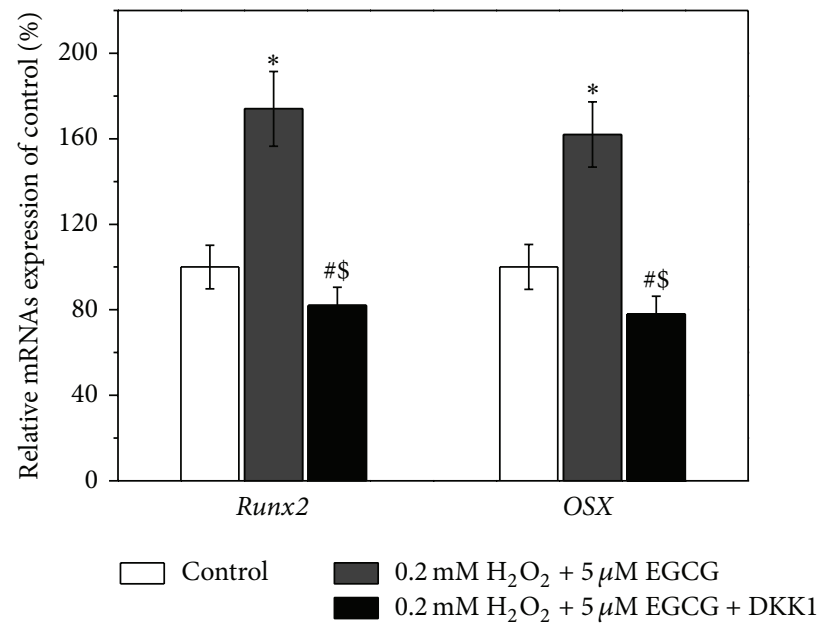

(e)

FIGURE 4: $5 \mu \mathrm{M}$ EGCG rescues the inhibition of osteogenic differentiation induced by $0.2 \mathrm{mM} \mathrm{H}_{2} \mathrm{O}_{2}$ involved in the Wnt pathway. (a) Western blot analysis of Wnt pathway-related regulators $\beta$-catenin and cyclin D1 in the cultures of experimental groups. (b) Relative protein expressions normalized to GAPDH in (a). Wnt inhibitor DKK-1 blocked the protective effects of EGCG on the inhibition of osteogenic differentiation by $0.2 \mathrm{mM} \mathrm{H}_{2} \mathrm{O}_{2}$ exposure, as evidenced by ALP activity (c), calcium contents (d), and relative mRNAs expression of Runx2 and OSX (e). Data were presented as mean \pm SEM. ${ }^{*} p<0.01$ and ${ }^{\#} p<0.05$ versus control, ${ }^{\&} p<0.01$ versus $0.2 \mathrm{mM} \mathrm{H}_{2} \mathrm{O}_{2}$ treatment alone in (b), and ${ }^{\$} p<0.01$ versus cotreatment of $0.2 \mathrm{mM} \mathrm{H}_{2} \mathrm{O}_{2}$ and $0.1 \mu \mathrm{M}$ EGCG. 


\section{Discussion}

MSCs are an attractive cell model for biomedical research over the past decade. MSCs are defined by positive expressions of CD29, CD44, CD73, CD90, and CD105 and negative expressions of CD19, CD34, and CD45 [19]. Thus, the positive expressions of CD29, CD44, and CD105 together with negative expressions of CD34 (Figure 1(a)) in our current study confirmed the identity of isolated cells as BMMSCs.

$\mathrm{H}_{2} \mathrm{O}_{2}$ is harmful for human cells because it induces oxidative stress [20,21]. As demonstrated by the cell viability assays, the damage induced by $\mathrm{H}_{2} \mathrm{O}_{2}$ on BM-MSCs was dose dependent, with the reduction beginning at $0.2 \mathrm{mM}$ (Figure 1(b)). The enhancement of cell viability after treatment with 5 and $10 \mu \mathrm{M}$ EGCG was observed, which is consistent with previous study [22]. Since our aim was to investigate the protective effects of EGCG against oxidative stress damage, BM-MSCs were then treated with $5 \mu$ M EGCG and $0.2 \mathrm{mM} \mathrm{H}_{2} \mathrm{O}_{2}$. The cell viability results clearly indicated that, under this condition, the protective effects of EGCG can be obviously observed (Figure 1(d)), which represented a reliable model for the following investigations.

The oxidative status of BM-MSCs after different treatments was further investigated using measurements of the levels of GSH, SOD activity, and MDA. GSH is a tripeptide, which acts as an important antioxidant to prevent damage to important cellular components induced by ROS [23]. SOD is another important antioxidant enzyme in living cells, which is able to catalyze the dismutation or partitioning of the superoxide $\left(\mathrm{O}_{2}^{-}\right)$radical into other less harmful compounds such as $\mathrm{H}_{2} \mathrm{O}_{2}$ [24]. MDA is the product of the degradation of polyunsaturated lipids induced by ROS [25]. Therefore, the observed decrease in the levels of GSH and SOD activity, together with the increase in the MDA level, after treatment with $\mathrm{H}_{2} \mathrm{O}_{2}$ indicated that $0.2 \mathrm{mM} \mathrm{H}_{2} \mathrm{O}_{2}$ can induce oxidative stress in BM-MSCs (Figure 2). When BMMSCs were treated with EGCG alone, the oxidative stress can be relieved. Furthermore, when the cells were cotreated with $\mathrm{H}_{2} \mathrm{O}_{2}$ and EGCG, the oxidative stress induced by $\mathrm{H}_{2} \mathrm{O}_{2}$ can no longer be observed (Figure 2).

After confirmation of the $\mathrm{H}_{2} \mathrm{O}_{2}$-induced oxidative stress and the antioxidative effect of EGCG, the effects of oxidative stress and EGCG on the osteogenic differentiation of BMMSCs were subsequently investigated. ALP activity and calcium deposition are commonly used as indicators for early and late stages of osteogenic differentiation [26, 27], and Runx 2 and OSX are key transcription factors for osteogenic differentiation [28]. The results shown in Figure 3 indicated that the oxidative stress induced by $\mathrm{H}_{2} \mathrm{O}_{2}$ exhibited a negative effect on the osteogenic differentiation of BM-MSCs, which is consistent with previous study [29]. The positive effect of EGCG on BM-MSC's osteogenic differentiation was possibly attributed to the antioxidative property of EGCG [22]. Thus, when the cells were treated with $\mathrm{H}_{2} \mathrm{O}_{2}$ and EGCG, EGCG can nullify the $\mathrm{H}_{2} \mathrm{O}_{2}$-induced adverse effects on the osteogenic differentiation of BM-MSCs (Figure 3).

Oxidative stress can cause irreversible changes in cellular proteins, resulting in permanent loss of cellular functions or even cell death. Wnt pathway has been reported to be involved in the damage caused by oxidative stress [30]. Hence, the involvement of Wnt pathway in the protective effects of EGCG from oxidative stress induced by $\mathrm{H}_{2} \mathrm{O}_{2}$ and the effect on BM-MSC's osteogenic differentiation was investigated. $\beta$ catenin and cyclin D1 are two important regulators in Wnt pathway. Activation of Wnt pathway increases nuclear and cytoplasmic levels of $\beta$-catenin, which initiates transcriptional activation of cyclin D1 and subsequently regulates cell behavior [31]. The results shown in Figures 4(a) and 4(b) suggested that Wnt pathway was involved in the EGCGinduced enhancement of osteogenic differentiation of BMMSCs, which was consistent with a previous study that reported the involvement of Wnt pathway in osteoblast differentiation and bone formation [32]. This notion was further confirmed by the results obtained with DKK-1, an effective Wnt pathway inhibitor, which also nullified the EGCGinduced enhancement of osteogenic differentiation of BMMSCs.

In fact, the discrepancies of experimental conditions in the current literatures contribute to the differences of reported biological effects of EGCG, including various administration routes, in vitro or in vivo studies, different cell lines, and different duration of exposure time. For in vitro observations, indeed there are many studies where EGCG at the concentrations below $1 \mu \mathrm{M}$ can exert certain effects, while there are also many studies where EGCG concentrations should be higher than $1 \mu \mathrm{M}$, even around micro molarity, to exhibit significant effects [33-38]. For in vivo studies, although the mean levels of EGCG achievable in human plasma were reported to not exceed $0.2 \mu \mathrm{M}$ [39], the samples in this study were administrated by a single oral dose of EGCG $(2 \mathrm{mg} / \mathrm{kg})$. In fact, we may enhance the EGCG concentrations in vivo to a comparable concentration to our study by many ways, such as intraperitoneal injection and increasing the administration times and doses.

\section{Conclusion}

Oxidative stress on BM-MSCs can be induced by $0.2 \mathrm{mM}$ $\mathrm{H}_{2} \mathrm{O}_{2}$, resulting in adverse effects on the viability and osteogenic differentiation, which can then be nullified by EGCG, as indicated by the results of ALP activity, calcium deposition, and the gene expressions of Runx2 and OSX. In addition, EGCG alone exhibited positive effects on the functions of BM-MSCs. We propose that EGCG exhibits these antioxidative effects via Wnt pathway. In summary, our results promoted the current understanding of the antioxidative effects of EGCG and indicated EGCG as a promising treatment strategy for bone repair therapies.

\section{Conflict of Interests}

The authors declare that there is no conflict of interests regarding the publication of this paper. 


\section{Acknowledgments}

This work was supported by the National Natural Science Foundation of China (81201392) and the Natural Science Foundation of Shandong Province (ZR2012HQ025).

\section{References}

[1] M. M. Brzóska, J. Rogalska, M. Galazyn-Sidorczuk, M. Jurczuk, A. Roszczenko, and M. Tomczyk, "Protective effect of Aronia melanocarpa polyphenols against cadmium-induced disorders in bone metabolism: a study in a rat model of lifetime human exposure to this heavy metal," Chemico-Biological Interactions, vol. 229, pp. 132-146, 2015.

[2] C.-L. Shen, J. K. Yeh, C. Samathanam et al., "Green tea polyphenols attenuate deterioration of bone microarchitecture in female rats with systemic chronic inflammation," Osteoporosis International, vol. 22, no. 1, pp. 327-337, 2011.

[3] C.-L. Shen, P. Wang, J. Guerrieri, J. K. Yeh, and J.-S. Wang, "Protective effect of green tea polyphenols on bone loss in middle-aged female rats," Osteoporosis International, vol. 19, no. 7, pp. 979-990, 2008.

[4] S. S. Moghe, S. Juma, V. Imrhan, and P. Vijayagopal, "Effect of blueberry polyphenols on 3T3-F442A preadipocyte differentiation," Journal of Medicinal Food, vol. 15, no. 5, pp. 448-452, 2012.

[5] D. Pandir, "Protective effect of (-)-epigallocatechin-3-gallate on capsaicin-induced DNA damage and oxidative stress in human erythrocyes and leucocytes in vitro," Cytotechnology, vol. 67, no. 2, pp. 367-377, 2015.

[6] M. Pae and D. Wu, "Immunomodulating effects of epigallocatechin-3-gallate from green tea: mechanisms and applications," Food \& Function, vol. 4, no. 9, pp. 1287-1303, 2013.

[7] B. N. Singh, S. Shankar, and R. K. Srivastava, "Green tea catechin, epigallocatechin-3-gallate (EGCG): mechanisms, perspectives and clinical applications," Biochemical Pharmacology, vol. 82, no. 12, pp. 1807-1821, 2011.

[8] Y. Wittrant, Y. Gorin, K. Woodruff et al., "High d(+)glucose concentration inhibits RANKL-induced osteoclastogenesis," Bone, vol. 42, no. 6, pp. 1122-1130, 2008.

[9] F. Wauquier, L. Leotoing, V. Coxam, J. Guicheux, and Y. Wittrant, "Oxidative stress in bone remodelling and disease," Trends in Molecular Medicine, vol. 15, no. 10, pp. 468-477, 2009.

[10] J.-H. Yun, E.-K. Pang, C.-S. Kim et al., "Inhibitory effects of green tea polyphenol (-)-epigallocatechin gallate on the expression of matrix metalloproteinase- 9 and on the formation of osteoclasts," Journal of Periodontal Research, vol. 39, no. 5, pp. 300-307, 2004

[11] B. Vali, L. G. Rao, and A. El-Sohemy, "Epigallocatechin-3-gallate increases the formation of mineralized bone nodules by human osteoblast-like cells," Journal of Nutritional Biochemistry, vol. 18, no. 5, pp. 341-347, 2007.

[12] J. R. Mauney, V. Volloch, and D. L. Kaplan, "Role of adult mesenchymal stem cells in bone tissue-engineering applications: current status and future prospects," Tissue Engineering, vol. 11, no. 5-6, pp. 787-802, 2005.

[13] H. Liu, G. W. Xu, Y. F. Wang et al., "Composite scaffolds of nano-hydroxyapatite and silk fibroin enhance mesenchymal stem cell-based bone regeneration via the interleukin 1 alpha autocrine/paracrine signaling loop," Biomaterials, vol. 49, pp. 103-112, 2015.

[14] E. Prosecká, M. Rampichová, A. Litvinec et al., "Collagen/hydroxyapatite scaffold enriched with polycaprolactone nanofibers, thrombocyte-rich solution and mesenchymal stem cells promotes regeneration in large bone defect in vivo," Journal of Biomedical Materials Research Part A, vol. 103, no. 2, pp. 671682, 2015.

[15] F.-F. Xu, H. Zhu, X.-M. Li et al., "Intercellular adhesion molecule-1 inhibits osteogenic differentiation of mesenchymal stem cells and impairs bio-scaffold-mediated bone regeneration in vivo," Tissue Engineering Part A, vol. 20, no. 19-20, pp. 2768 2782, 2014.

[16] P. Hua, Y.-Y. Wang, L.-B. Liu et al., "In vivo magnetic resonance imaging tracking of transplanted superparamagnetic iron oxide-labeled bone marrow mesenchymal stem cells in rats with myocardial infarction," Molecular Medicine Reports, vol. 11, no. 1, pp. 113-120, 2014.

[17] Q. Song, R. Xu, Q. Zhang, M. Ma, and X. Zhao, "Therapeutic effect of transplanting bone mesenchymal stem cells on the hind limbs' motor function of rats with acute spinal cord injury," International Journal of Clinical and Experimental Medicine, vol. 7, no. 1, pp. 262-267, 2014.

[18] F. Yin, M. Battiwalla, S. Ito et al., "Bone marrow mesenchymal stromal cells to treat tissue damage in allogeneic stem cell transplant recipients: correlation of biological markers with clinical responses," STEM CELLS, vol. 32, no. 5, pp. 1278-1288, 2014.

[19] Y. Li, W. Xu, J. Yan et al., "Differentiation of human amniotic fluid-derived mesenchymal stem cells into type II alveolar epithelial cells in vitro," International Journal of Molecular Medicine, vol. 33, no. 6, pp. 1507-1513, 2014.

[20] H. Sies, "Role of metabolic $\mathrm{H}_{2} \mathrm{O}_{2}$ generation: redox signaling and oxidative stress," The Journal of Biological Chemistry, vol. 289, no. 13, pp. 8735-8741, 2014.

[21] G. W. Konat, " $\mathrm{H}_{2} \mathrm{O}_{2}$-induced higher order chromatin degradation: a novel mechanism of oxidative genotoxicity," Journal of Biosciences, vol. 28, no. 1, pp. 57-60, 2003.

[22] P. Jin, H. Wu, G. Xu, L. Zheng, and J. Zhao, "Epigallocatechin-3gallate (EGCG) as a pro-osteogenic agent to enhance osteogenic differentiation of mesenchymal stem cells from human bone marrow: an in vitro study," Cell and Tissue Research, vol. 356, no. 2, pp. 381-390, 2014.

[23] A. Pompella, A. Visvikis, A. Paolicchi, V. De Tata, and A. F. Casini, "The changing faces of glutathione, a cellular protagonist," Biochemical Pharmacology, vol. 66, no. 8, pp. 1499-1503, 2003.

[24] S. Gagliardi, E. Cova, A. Davin et al., "SOD1 mRNA expression in sporadic amyotrophic lateral sclerosis," Neurobiology of Disease, vol. 39, no. 2, pp. 198-203, 2010.

[25] A. Valenzuela, "The biological significance of malondialdehyde determination in the assessment of tissue oxidative stress," Life Sciences, vol. 48, no. 4, pp. 301-309, 1991.

[26] X. Hu, K.-G. Neoh, Z. Shi, E.-T. Kang, C. Poh, and W. Wang, "An in vitro assessment of titanium functionalized with polysaccharides conjugated with vascular endothelial growth factor for enhanced osseointegration and inhibition of bacterial adhesion," Biomaterials, vol. 31, no. 34, pp. 8854-8863, 2010.

[27] X. Hu, K. G. Neoh, J. Zhang, E.-T. Kang, and W. Wang, "Immobilization strategy for optimizing VEGF's concurrent bioactivity towards endothelial cells and osteoblasts on implant surfaces," Biomaterials, vol. 33, no. 32, pp. 8082-8093, 2012.

[28] H. Liu, Q. Sun, C. Wan, L. Li, L. Zhang, and Z. Chen, "MicroRNA-338-3p regulates osteogenic differentiation of mouse bone marrow stromal stem cells by targeting Runx2 and Fgfr2," 
Journal of Cellular Physiology, vol. 229, no. 10, pp. 1494-1502, 2014.

[29] W.-K. Kim, V. Meliton, N. Bourquard, T. J. Hahn, and F. Parhami, "Hedgehog signaling and osteogenic differentiation in multipotent bone marrow stromal cells are inhibited by oxidative stress," Journal of Cellular Biochemistry, vol. 111, no. 5, pp. 1199-1209, 2010.

[30] G.-Z. Tao, N. Lehwald, K. Y. Jang et al., "Wnt/ $\beta$-catenin signaling protects mouse liver against oxidative stress-induced apoptosis through the inhibition of forkhead transcription factor $\mathrm{FoxO}_{3}$," The Journal of Biological Chemistry, vol. 288, no. 24, pp. 17214-17224, 2013.

[31] J. Tian, H. He, and G. Lei, "Wnt/ $\beta$-catenin pathway in bone cancers," Tumor Biology, vol. 35, no. 10, pp. 9439-9445, 2014.

[32] T. F. Day, X. Guo, L. Garrett-Beal, and Y. Yang, "Wnt/ $\beta$-catenin signaling in mesenchymal progenitors controls osteoblast and chondrocyte differentiation during vertebrate skeletogenesis," Developmental Cell, vol. 8, no. 5, pp. 739-750, 2005.

[33] M. Lorenz, L. Klinkner, G. Baumann, K. Stangl, and V. Stangl, "Endothelial NO production is mandatory for epigallocatechin3-gallate-induced vasodilation: results from eNOS knockout $\left(\mathrm{eNOS}^{-/-}\right.$) mice," Journal of Cardiovascular Pharmacology, vol. 65 , no. 6, pp. 607-610, 2015.

[34] J. Y. Jeong, S. Suresh, M. Jang et al., "Epigallocatechin-3gallate suppresses the lipid deposition through the apoptosis during differentiation in bovine bone marrow mesenchymal stem cells," Cell Biology International, vol. 39, no. 1, pp. 52-64, 2015.

[35] L. D’Angelo, G. Piazzi, A. Pacilli et al., "A combination of eicosapentaenoic acid-free fatty acid, epigallocatechin-3-gallate and proanthocyanidins has a strong effect on mTOR signaling in colorectal cancer cells," Carcinogenesis, vol. 35, no. 10, pp. 2314-2320, 2014.

[36] N. Akhtar and T. M. Haqqi, "Epigallocatechin-3-gallate suppresses the global interleukin-1 $\beta$-induced inflammatory response in human chondrocytes," Arthritis Research \& Therapy, vol. 13, no. 3, article R93, 2011.

[37] M. Pae, Z. Ren, M. Meydani, F. Shang, S. N. Meydani, and D. Wu, "Epigallocatechin-3-gallate directly suppresses $\mathrm{T}$ cell proliferation through impaired IL-2 utilization and cell cycle progression," The Journal of Nutrition, vol. 140, no. 8, pp. 1509$1515,2010$.

[38] J. Kang, H. Cheng, J. Ji, J. Incardona, and D. Rampe, "In vitro electrocardiographic and cardiac ion channel effects of (-)epigallocatechin-3-gallate, the main catechin of green tea," The Journal of Pharmacology and Experimental Therapeutics, vol. 334, no. 2, pp. 619-626, 2010.

[39] M.-J. Lee, P. Maliakal, L. Chen et al., "Pharmacokinetics of tea catechins after ingestion of green tea and (-)-epigallocatechin3-gallate by humans: formation of different metabolites and individual variability," Cancer Epidemiology Biomarkers \& Prevention, vol. 11, no. 10, part 1, pp. 1025-1032, 2002. 

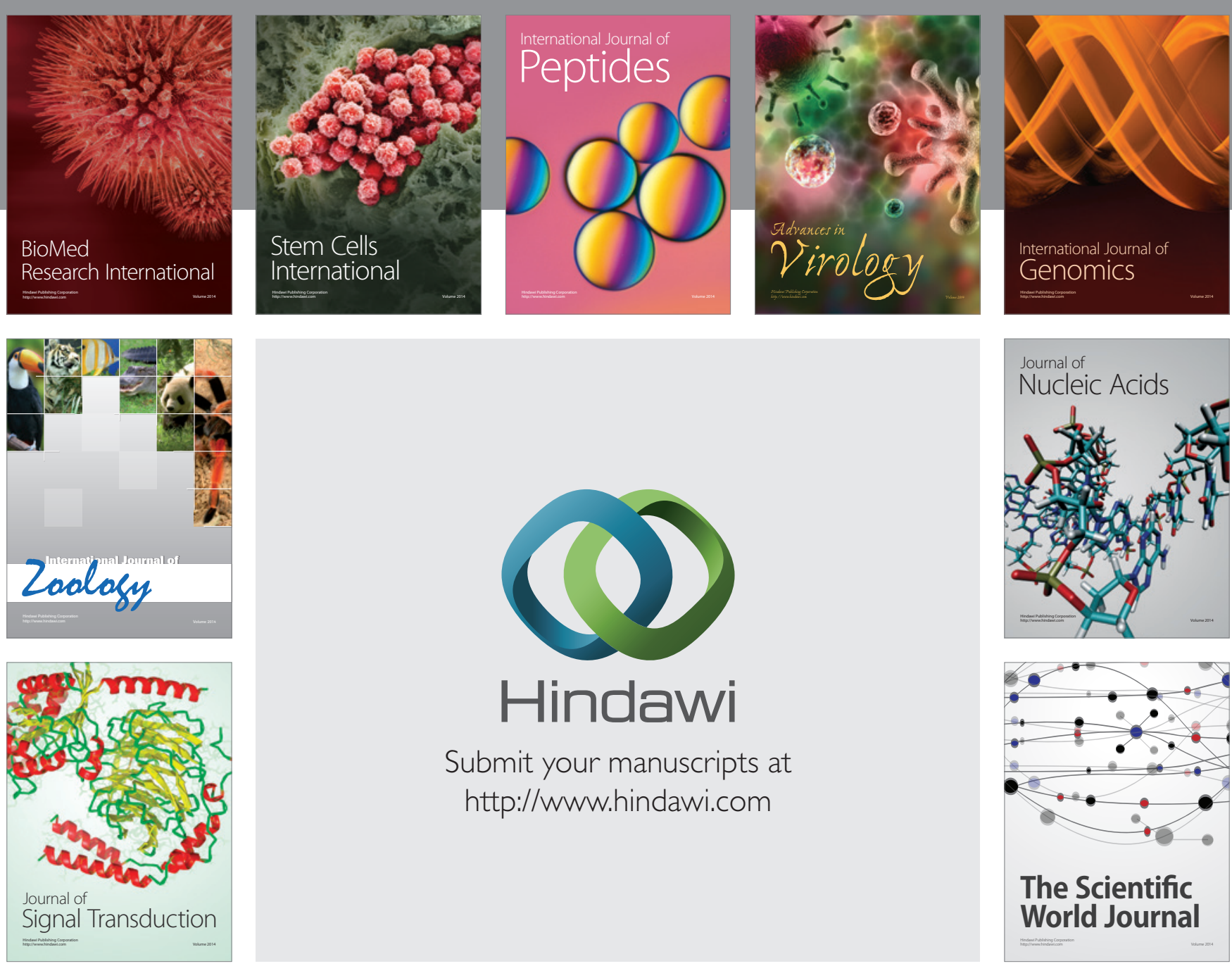

Submit your manuscripts at

http://www.hindawi.com
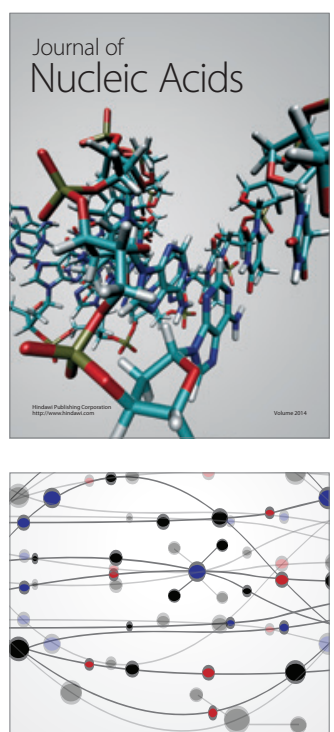

The Scientific World Journal
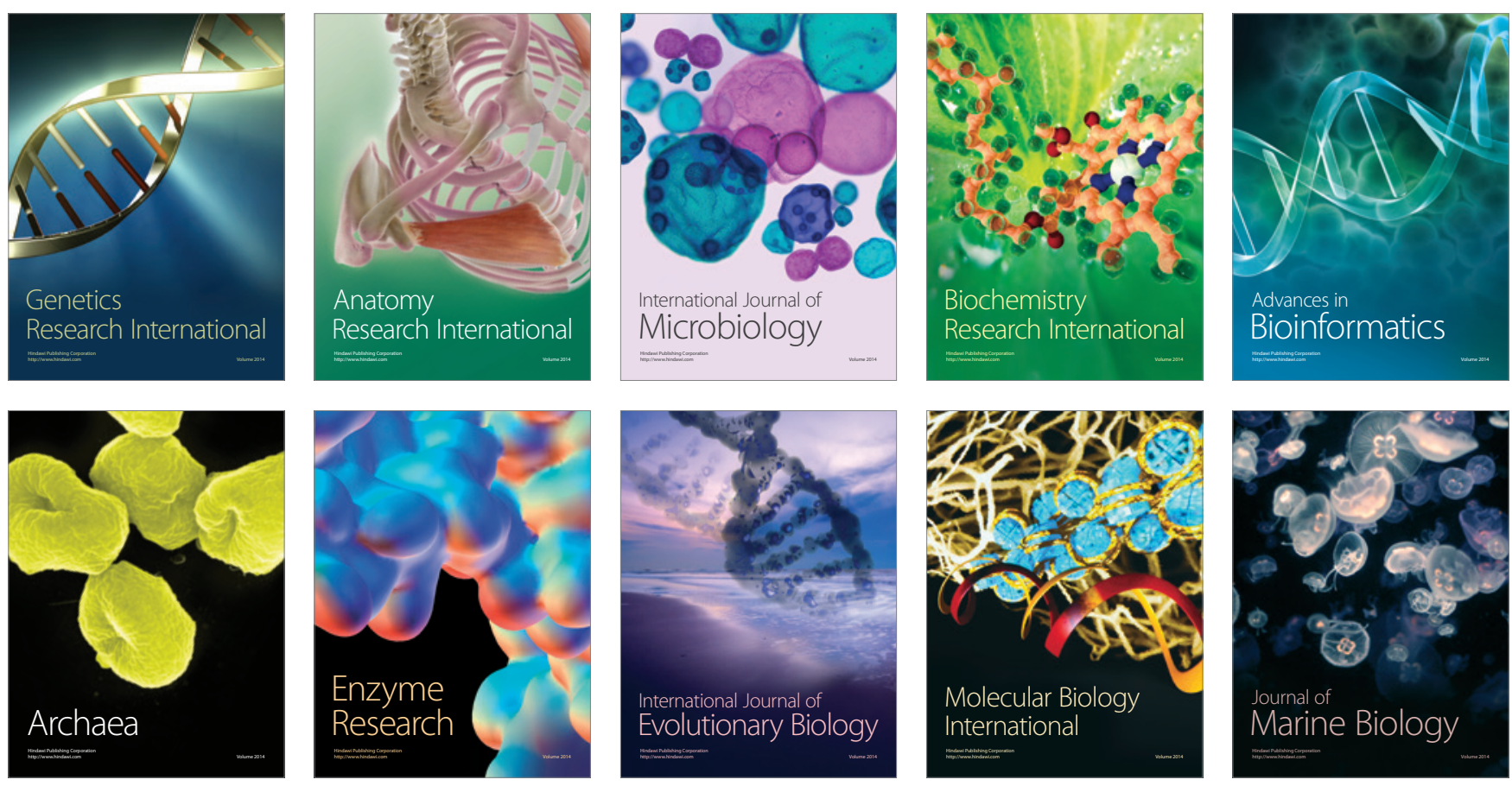